\title{
Influência da Administração Militar nas Escolas Públicas de Ensino Básico
}

\author{
Andreia Pereira Bomfim ${ }^{l}$; Arielle Barros Damasceno ${ }^{2}$; Luciene Simplício dos Santos Soares ${ }^{l}$;
} Luzia Coelho Rodrigues ${ }^{3}$; Sieton Soares Fernandes ${ }^{I}$

\begin{abstract}
Resumo: este trabalho propõe uma discussão sobre uma possível influência da Gestão Militar sobre o desempenho dos discentes em escolas públicas, buscando responder à seguinte questão norteadora: quais os fatores definidores do desempenho de escolas públicas, atuantes na gestão militar, que contribuem favoravelmente para a eficácia de suas funções educativas demonstrados nas pesquisas do IDEB e do SIEPE. Os efeitos progressivos da educação militar interferem positivamente na disciplina e responsabilidade do aluno. Esse impacto demonstra a preferência do discente pela instituição e de como sua visão de futuro constitui reflexo dos conceitos desse tipo de gestão.
\end{abstract}

Palavras-chave: Administração militar, desempenho acadêmico, escolas públicas.

\section{The Influence of Military Administration in Public Schools of Basic Education}

\begin{abstract}
This paper proposes a discussion about a possible influence of Military Management on the performance of students in public schools, seeking to answer the following guiding question: what are the defining factors of the performance of public schools, active in military management, that contribute favorably to the effectiveness of their educational functions demonstrated in the IDEB and SIEPE surveys. The progressive effects of military education interfere positively with students discipline and responsibility. This impact demonstrates the student's preference for the institution and how their vision for the future is a reflection of the concepts of this type of management.
\end{abstract}

Keywords: Military administration, academic performance, public schools.

\section{Introdução}

Com a maioria da população brasileira dependendo do Estado para a oferta da Educação Básica (INEP, 2013) à sua família, muito ainda se fala em baixa qualidade do ensino e do mau rendimento dos alunos egressos de escolas públicas (SIQUEIRA, 2010), sendo recorrentes as discussões sobre a qualidade da educação, principalmente no ensino fundamental e ensino médio.

\footnotetext{
${ }^{1}$ Graduação em Administração Pública pela Universidade Federal do Vale do São Francisco;

${ }^{2}$ Graduação em Matemática pela Universidade de Pernambuco.

${ }^{3}$ Mestre em Administração (UFBA), especialista em Capacitação Pedagógica de Professores (UFRPE) e graduada em Letras (UPE). luciene.simplicio@univasf.edu.br;
} 
$\mathrm{Na}$ contramão dessa grande massa, encontram-se algumas escolas que, mesmo sendo públicas, parecem fugir a essa regra. Tratam-se das escolas administradas por militares (BENEVIDES; SOARES, 2015), que ano após ano, apresentam resultados positivos demonstrados em pesquisas, a exemplo do Índice de Desenvolvimento da Educação Básica (IDEB) e do Sistema de Informações da Educação de Pernambuco (SIEPE), além de provas como o Exame Nacional do Ensino Médio (ENEM) e vestibular em geral.

Diante disso, este trabalho propõe uma discussão sobre uma possível influência da Gestão Militar sobre o desempenho dos discentes em escolas públicas, buscando responder à seguinte questão norteadora: quais os fatores definidores do desempenho de escolas públicas, atuantes na gestão militar, que contribuem favoravelmente para a eficácia de suas funções educativas demonstrados nas pesquisas do IDEB e do SIEPE.

\section{Justificativa}

Justifica-se a realização da pesquisa com o intuito de entender os fatores que contribuem para que Colégios Militares, que são escolas públicas da rede estadual ou federal, como tantas outras existentes, sejam destaques em sua atuação. Como exemplo, cita-se o Colégio da Polícia Militar de Petrolina, que possui um dos mais altos índices do IDEB do Estado, atingindo no ano de 2015 uma nota maior do que a meta prevista para o ano de 2021, estando assim em primeiro lugar na cidade, à frente inclusive de escolas privadas da região. Situação essa que desperta interesse em conhecer quais as práticas adotadas na instituição que influenciam o desempenho apontado pelas pesquisas. Aliado a isso, pretende-se identificar o nível de satisfação dos docentes, e o reflexo do trabalho desenvolvido na instituição sobre o desempenho dos alunos.

O papel de uma escola transcende o fato de apenas ensinar o conteúdo previsto a cada segmento, buscando a aprovação no vestibular e o ingresso no mercado de trabalho, estendendo-se, também, às questões sociais e ao desenvolvimento humano dos seus alunos, não se limitando ao conteúdo acadêmico propriamente dito, mas alcançando os valores essenciais para a vida em meio comum. 
O objetivo geral do estudo é identificar, a partir da percepção de professores e alunos, as contribuições do modelo de gestão adotado pelo Colégio da Polícia Militar de Petrolina no índice de desempenho apresentado por seus estudantes.

Os objetivos específicos que norteiam a pesquisa são: a) Apresentar a prática pedagógica e administrativa adotada pelo Colégio da Polícia Militar de Petrolina e os índices de desempenho utilizados em avaliações externas; b) Identificar o nível de satisfação do corpo docente e discente do Colégio da Polícia Militar de Petrolina, em relação à prática pedagógica e administrativa.

\section{Desempenho das Escolas Militares segundo o ENEM}

As escolas públicas administradas por gestões militares vêm se destacando em todas as regiões do Brasil, em particular, em Petrolina - PE, onde o Colégio da Polícia Militar obtém, ano após ano, índices satisfatórios de proficiência e bons resultados em provas como o ENEM, se comparados a outras instituições públicas da cidade e do Estado.

Muitos fatores são colocados em questão quando se trata dos resultados obtidos pela escola, a exemplo de teste seletivo, que como o próprio nome diz, seleciona seu público-alvo; respeito à hierarquia; regras e normas disciplinares estabelecidas, professores capacitados e alguns com salários diferenciados.

Poucos são os estudos feitos no Brasil que procuram mostrar o que leva as escolas militares a apresentarem resultados satisfatórios, mas embasados em alguns dados disponíveis pelo Ministério da Educação esse estudo busca discutir e entender o que de fato é relevante para a elevação do desempenho nessas instituições.

Segundo Benevides e Soares (2015), pedagogos e gestores vêm debatendo sobre o crescimento do número de escolas militares no Brasil, acreditando os autores que esse crescimento tem relação com o alto nível de desempenho dos estudantes desses colégios e com a metodologia adotada. Não se tratam de fenômeno recente, tampouco isolado, os bons resultados dos alunos dos colégios militares brasileiros em exames nacionais, vestibulares e testes. 
Criado em 1998, o ENEM avalia o desempenho dos estudantes ao concluírem a educação básica com o objetivo de melhorar o nível de ensino das escolas brasileiras. Desde o ano de 2009, passou a ser o principal mecanismo de acesso dos estudantes ao ensino superior no país. A pontuação alcançada pelas escolas no ENEM é um forte indicativo no que se refere ao nível de ensino, senão o mais conhecido referencial comparativo de desempenho.

Outro fato interessante é que esses resultados trazem indicadores como nível socioeconômico dos alunos e a formação dos docentes das escolas, dentre outros dados. Os resultados do último ENEM catalogado referem ao ano 2015 e estão divididos por competências.

Para fins classificatórios nessa pesquisa, foram usados: "desempenho, linguagens e outras tecnologias", por ser a mais geral das classificações disponíveis, sendo as demais bastante específicas (redação, matemática, ciências humanas e ciências da natureza), contudo, a classificação ${ }^{1}$ das escolas militares ainda se destaca independentemente do critério utilizado na pesquisa, conforme demonstrado na tabela 1 .

Tabela 1 - Classificação de Escolas Militares no ENEM

\begin{tabular}{c|l|c|c|c}
\hline Clas.* & \multicolumn{1}{|c|}{ Escola } & Rede & Localização & $\begin{array}{c}\text { Média } \\
\text { ENEM }\end{array}$ \\
\hline $\mathbf{4}^{\text {a }}$ & CEEM Tiradentes & Estadual & Porto Alegre-RS & 619,27 \\
\hline $\mathbf{1 2}^{\mathbf{a}}$ & Colégio Militar de Belo Horizonte & Federal & Belo Horizonte-MG & 606,92 \\
\hline $\mathbf{1 5}^{\mathbf{a}}$ & Escola Prep. de Cadetes do Ar & Federal & Barbacena-MG & 606,58 \\
\hline $\mathbf{2 1}^{\mathbf{a}}$ & Colégio Militar de Porto Alegre & Federal & Porto Alegre-RS & 604,62 \\
\hline $\mathbf{2 7}^{\text {a }}$ & Colégio Militar de Salvador & Federal & Salvador-BA & 599,44 \\
\hline $\mathbf{3 1}^{\mathbf{a}}$ & Colégio Militar de Campo Grande & Federal & Campo Grande-MS & 596,18 \\
\hline $\mathbf{4 8}^{\text {a }}$ & Colégio Militar de Fortaleza & Federal & Fortaleza-CE & 591,89 \\
\hline $\mathbf{5 3}^{\text {a }}$ & Colégio Militar de Curitiba & Federal & Curitiba-PR & 590,58 \\
\hline $\mathbf{5 5}^{\mathbf{a}}$ & Colégio Militar de Santa Maria & Federal & Santa Maria-RS & 590,48 \\
\hline $\mathbf{5 7}^{\mathbf{a}}$ & Colégio Tiradentes Ijuí & Estadual & Ijuí-RS & 590,11 \\
\hline $\mathbf{5 9}^{\mathbf{a}}$ & Colégio Militar Dom Pedro II & Estadual & Brasília-DF & 590,07 \\
\hline $\mathbf{6 3}^{\mathbf{a}}$ & Colégio Militar do Recife & Federal & Recife-PE & 589,34 \\
\hline $\mathbf{6 5}^{\mathbf{a}}$ & Colégio Militar de Juiz de Fora & Federal & Juiz de Fora-MG & 598,05 \\
\hline $\mathbf{7 0}^{\mathbf{a}}$ & Colégio Militar do Rio de Janeiro & Federal & Rio de Janeiro-RJ & 586,49 \\
\hline $\mathbf{7 2}^{\mathbf{a}}$ & CPM Cel. Felippe de S. Miranda & Estadual & Curitiba-PR & 586,19 \\
\hline $\mathbf{8 3}^{\mathbf{a}}$ & Colégio Militar de Brasília & Federal & Brasília-DF & 582,70 \\
\hline $\mathbf{8 6}^{\mathbf{a}}$ & Colégio Tiradentes de Sta. Maria & Estadual & Santa Maria-RS & 582,15 \\
\hline $\mathbf{9 6}^{\mathbf{a}}$ & Colégio Militar de Manaus & Federal & Manaus-AM & 579,79 \\
\hline
\end{tabular}

Fonte: INEP(2015)

\footnotetext{
${ }^{1}$ Classificação das escolas militares dentre as 100 (cem) primeiras colocadas entre as escolas públicas federais e estaduais do Brasil
} 
Pela Classificação ENEM, das escolas militares dentre as 100 primeiras colocadas entre as escolas públicas federais e estaduais do Brasil, nota-se a predominância de colégios militares sob a administração do Exército Brasileiro (federais). Dentre os colégios militares estaduais (a cargo das polícias ou bombeiros militares), a Brigada Militar do Rio Grande do Sul é a que tem o maior número de escolas sob sua administração (três no total).

Os indicadores apontam cerca de $20 \%$ das melhores escolas públicas do país sob a administração militar, sendo que este percentual pode aumentar ainda mais quando se aplica outros critérios de busca no sistema ENEM. Registra-se que as outras escolas públicas que dividem as melhores posições com as escolas militares são, em sua maioria, escolas técnicas e colégios de aplicação federais. Em todas essas instituições, o ingresso de discente acontece por meio de processo seletivo.

\section{Índice de Qualidade da Educação em Escolas Militares, segundo o IDEB}

O IDEB foi Instituído em 2007, pelo Instituto Nacional de Estudos e Pesquisas Educacionais Anísio Teixeira (INEP), através do Ministério da Educação, e é considerado o indicador de qualidade da educação básica no Brasil, calculado com base no fluxo escolar e nas médias de desempenho nas avaliações, sendo também o instrumento utilizado para estabelecer as metas educacionais a serem alcançadas para o futuro. Através das consultas no site oficial do INEP, podem-se usar diversos critérios de pesquisa. Ainda assim, não se pode exibir uma relação de todas as escolas nacionais, o que facilitaria a exibição de um panorama das escolas militares de todo o país. Ante essa limitação, como já dito, foi utilizado o estado de Pernambuco como referencial, destacando sua capital e a cidade de Petrolina, região do sertão do médio São Francisco, sede da escola unidade de estudo.

A tabela 2 faz um comparativo entre o índice médio nacional e estadual de todas as escolas públicas e das escolas militares dos Estados de Pernambuco e da Bahia, ao final do ensino fundamental ( $9^{\circ}$ ano). Um comparativo ao final do $3^{\circ}$ Ano do Ensino Médio seria desejável, contudo, o sistema IDEB não disponibiliza tal consulta para todas as unidades 
escolares, o que tornaria o referencial incompleto ante a ausência do referido índice para algumas das escolas.

Tabela 2 - Classificação das Escolas Militares no IDEB $^{2}$ por cidade

\begin{tabular}{|c|c|c|c|c|c|c|c|c|c|}
\hline \multirow{2}{*}{ Ord. } & \multirow{2}{*}{$\begin{array}{c}\text { Região / Escolas } \\
\text { Federais e Estaduais }\end{array}$} & \multirow{2}{*}{ Localização } & \multirow{2}{*}{$\begin{array}{c}\text { Ranking } \\
\text { 2015* }\end{array}$} & \multicolumn{6}{|c|}{ IDEB atingido*** } \\
\hline & & & & 2005 & 2007 & 2009 & 2011 & 2013 & 2015 \\
\hline 1.0 .0 .0 & $\begin{array}{l}\text { Média - Escolas } \\
\text { Públicas do Brasil }\end{array}$ & Brasil & - & 3.2 & 3.5 & 3.7 & 3.9 & 4.0 & 4.2 \\
\hline 1.1.0.0 & $\begin{array}{l}\text { Média - Escolas } \\
\text { Públicas da Bahia }\end{array}$ & Bahia & - & 2.6 & 2.8 & 2.9 & 3.1 & 3.2 & 3.4 \\
\hline 1.1 .1 .0 & $\begin{array}{l}\text { Média - Escolas } \\
\text { Públcias de Salvador }\end{array}$ & Bahia & - & 2.5 & 2.7 & 2.7 & 2.7 & 2.9 & 3.1 \\
\hline 1.1.1.1 & $\begin{array}{lcr}\text { Colégio Militar } & \text { de } \\
\text { Salvador } \quad \text { (federal } & - \\
\text { Exército Brasileiro) } & \\
\end{array}$ & Salvador-BA & $1^{\circ}$ lugar & 7.0 & 7.2 & 7.1 & 7.2 & 7.1 & 7.5 \\
\hline 1.1 .1 .2 & $\begin{array}{lcc}\text { CPM } & \text { Unidade } & \text { II } \\
\text { Lobato } \quad \text { (estadual } & - \\
\text { Polícia } & \text { Militar) } & \\
\end{array}$ & Salvador-BA & $2^{\circ}$ lugar & 4.1 & 4.1 & 4.9 & 5.0 & 4.3 & 4.7 \\
\hline 1.1 .1 .3 & $\begin{array}{l}\text { CPM Unidade I } \\
\text { Dendezeiros (estadual - } \\
\text { Polícia Militar) }\end{array}$ & Salvador-BA & $3^{\circ}$ lugar & 4.4 & 3.8 & 4.6 & 5.3 & 4.7 & - \\
\hline 1.1 .1 .4 & $\begin{array}{l}\text { CPM João Florêncio } \\
\text { Gomes (estadual - } \\
\text { Polícia Militar) }\end{array}$ & Salvador-BA & $7^{\circ}$ lugar & - & 2.8 & 3.6 & 4.5 & 4.1 & 3.7 \\
\hline 1.1 .2 .0 & $\begin{array}{l}\text { Média }- \text { Escolas } \\
\text { Públicas de Juazeiro }\end{array}$ & Juazeiro-BA & - & 2.5 & 2.9 & 3.1 & 3.2 & 3.3 & 3.7 \\
\hline 1.1.2.1 & $\begin{array}{ll}\text { CPM Alfredo } & \text { Vianna } \\
\text { (estadual }- & \text { Polícia } \\
\text { Militar) } & \end{array}$ & Juazeiro-BA & $1^{\circ}$ lugar & - & 4.8 & 5.0 & - & 5.6 & 5.1 \\
\hline 1.2 .0 .0 & $\begin{array}{lr}\text { Média }- & \text { Escolas } \\
\text { Públicas } & \text { de } \\
\text { Pernambuco } & \\
\end{array}$ & Pernambuco & - & 2.4 & 2.6 & 3.0 & 3.2 & 3.4 & 3.8 \\
\hline 1.2.1.0 & $\begin{array}{l}\text { Média }- \text { Escolas } \\
\text { Públicas de Recife }\end{array}$ & Pernambuco & - & 2.4 & 2.3 & 2.8 & 3.1 & 3.5 & 3.9 \\
\hline 1.2 .1 .1 & $\begin{array}{lcr}\begin{array}{l}\text { Colégio } \\
\text { Recife }\end{array} & \begin{array}{l}\text { Militar } \\
\text { (federal }\end{array} & \text { do } \\
\text { Exército Brasileiro) } & \\
\end{array}$ & Recife-PE & $2^{\circ}$ lugar & - & 7.2 & 6.6 & 6.6 & 6.7 & 6.8 \\
\hline 1.2 .1 .2 & $\begin{array}{l}\text { CPM Recife (estadual - } \\
\text { Polícia Militar) }\end{array}$ & Recife-PE & $4^{\circ}$ lugar & 4.1 & 4.7 & 5.2 & 4.8 & 5.7 & 5.6 \\
\hline 1.2.2.0 & $\begin{array}{l}\text { Média }- \text { Escolas } \\
\text { Públicas de Petrolina }\end{array}$ & Petrolina-PE & - & 2.7 & 3.1 & 3.6 & 3.7 & 4.1 & 4.5 \\
\hline 1.2 .2 .1 & $\begin{array}{lll}\text { CPM }- & \text { Anexo } & \text { I } \\
\text { Petrolina (estadual } & - \\
\text { Polícia Militar) } & \\
\end{array}$ & Petrolina-PE & $1^{\circ}$ lugar & - & - & - & 4.8 & 5.4 & 6.2 \\
\hline
\end{tabular}

Fonte: INEP (2016)

A partir da tabela de classificação IDEB, por cidade de localização da Unidade Escolar, considerando as escolas públicas da rede federal e estadual, percebe-se que sete das

\footnotetext{
2 Classificação por cidade de localização da Unidade Escolar, considerando as escolas públicas da rede federal e estadual.
} 
oito escolas analisadas, localizadas nos Estados da Bahia e de Pernambuco, apresentaram, para os anos de 2005 a 2015, índice superior ao da média nacional, excetuando apenas o CPM João Florêncio Gomes, localizado na capital da Bahia, para os anos de 2007, 2009 e 2015, o qual atingiu IDEB idêntico à média estatal no ano de 2007, porém superior nos demais.

Entre as escolas apresentadas na tabela acima, todas as oito escolas militares ranqueadas estão, sem exceção, sempre entre as dez melhores colocações dentre as escolas públicas, conforme pode se observar nos índices apresentados acima.

No sertão do Médio São Francisco, os dois colégios militares existentes, localizados nas cidades de Juazeiro-BA e Petrolina-PE, sob a administração dos militares dos respectivos Estados, invariavelmente, vêm ocupando a primeira colocação dentre as escolas públicas locais.

\section{Método}

O campo de estudo foi a Escola Militar de Petrolina, estado de Pernambuco, contextualizando o desempenho da instituição e as contribuições da gestão militar nos resultados obtidos, a partir da percepção de professores e alunos. Para embasar a temática, foi realizada pesquisa documental em dois indicadores mais utilizados para avaliação escolar, no sistema educacional brasileiro, ambos em nível nacional, quais sejam o ENEM e o IDEB.

Os dados primários foram coletados entre os dias 07 e 09 de março de 2017 por meio de questionário com perguntas objetivas, de múltipla escolha, abordando questões sobre a administração da escola, seu regimento interno e os resultados obtidos nas avaliações externas: ENEM e IDEB. Participaram da pesquisa 10 professores num universo de 35 , e 30 alunos dentro de um total de 494, da instituição pesquisada.

As informações foram analisadas por meio de análise de conteúdo, técnica que aceita tanto métodos quantitativos quanto qualitativos (VERGARA, 2010; BARDIN, 2006).

\section{Resultados E Discussão}

490 Id on Line Rev. Mult. Psic. V.11, N. 37., 2017 - ISSN 1981-1179 Edição eletrônica em http://idonline.emnuvens.com.br/id 
O Colégio da Polícia Militar de Petrolina oferta vagas destinadas aos dependentes de militares e também aos civis, condicionadas à aprovação em teste seletivo. Isso, por si só, já é um diferencial diante das outras escolas, pois o estudante que se propõe a passar pelo teste se prepara previamente, em função dos altos índices de concorrência. A escola possui infraestrutura adequada, tem um regime de funcionamento especial, onde várias regras e normas devem ser obedecidas por alunos e professores.

Além do colégio Militar de Petrolina, sertão do Médio São Francisco, existe outro na cidade de Juazeiro-BA, município vizinho. As duas instituições de ensino, sob a administração dos militares dos respectivos Estados, ocupam primeiro lugar na classificação IDEB das escolas públicas locais (IDEB, 2015). A prática pedagógica e administrativa da instituição, a partir da percepção de professores e discentes, passa a ser apresentada.

\section{Percepção de professores sobre a prática administrativa e pedagógica}

Em relação à prática pedagógica e administrativa adotada no Colégio da Polícia Militar de Petrolina, os respondentes atribuíram respostas avaliativas para a gestão de recursos, segurança, comunicação, desempenho dos estudantes e influência da gestão militar no desempenho discente.

No que tange à obtenção de recursos, numa escala avaliativa de cinco níveis entre "nada fácil” e "extremamente fácil”, os resultados estão demonstrados na figura 1.

Figura 1 - Percepção de professores sobre a obtenção de recursos

\section{Recursos}

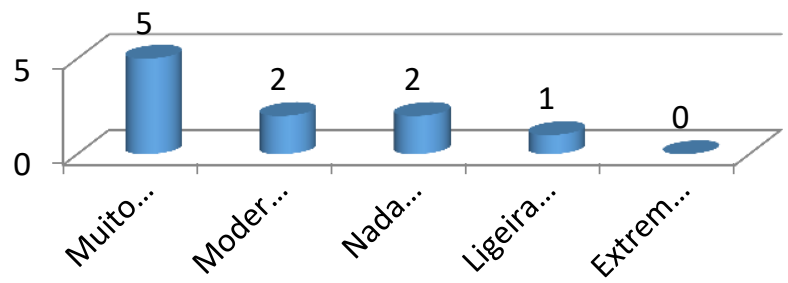

Fonte: dados da pesquisa (2017) 
Analisando os resultados mostrados no gráfico acima, observa-se que metade dos professores entrevistados considerou satisfatória a obtenção dos recursos necessários para funcionamento de suas atividades. Essa resposta essencialmente positiva, possivelmente é decorrente do fato da instituição possuir recursos financeiros próprios gerados a partir da cobrança de taxas mensais aos pais ou responsáveis direto pelos discentes. A verba proveniente da "caixa escolar" é movimentada pela gestão do colégio através de processo licitatório.

Outro quesito positivamente avaliado foi segurança no ambiente organizacional, com $80 \%$ dos respondentes avaliando entre "muito seguro" e "extremamente seguro" na escala de cinco pontos.

No que tange à comunicação interna, a partir da percepção de professores, percebe-se que os respondentes estão satisfeitos com o feedback da gestão, conforme demonstrado na figura 2. Os resultados sugerem que a integração entre gestores e docentes contribui satisfatoriamente para o avanço pedagógico da escola, bem como o ambiente escolar construído em conjunto com a gestão, tem contribuído para a manutenção e apoio aos professores em suas atividades.

Figura 2 - Percepção docente sobre feedback da direção da escola

\section{Utilidade do feedback}

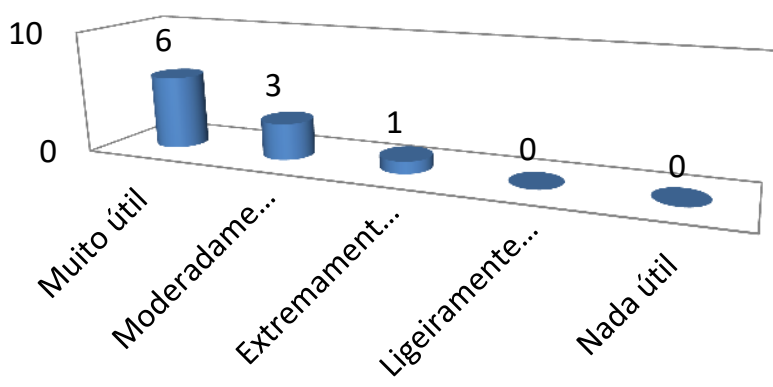

Fonte: Dados da pesquisa (2017)

Perguntado sobre a coerência entre o desempenho dos alunos do Colégio Militar de Petrolina, conforme classificação IDEB, resultados da figura 3 sugerem elevado nível de satisfação dos professores com o rendimento de seus alunos. 
Figura 3 - Coerência entre expectativa docente e desempenho discente

Expectativa docente $\mathrm{x}$ desempenho discente

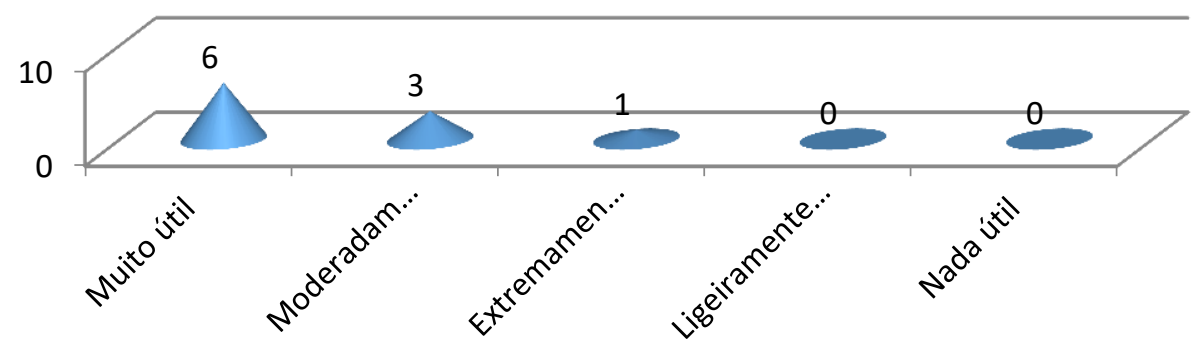

Fonte: Dados da pesquisa (2017)

Por fim, foi perguntado aos professores se eles acreditam que a administração militar tinha influência direta no comportamento dos alunos e nos resultados apresentados pela escola. Os resultados estão demonstrados na figura 4.

Figura 4 - Percepção docente sobre influência da administração militar no desempenho discente

\section{Influência da administração militar no comportamento e resultado dos alunos}

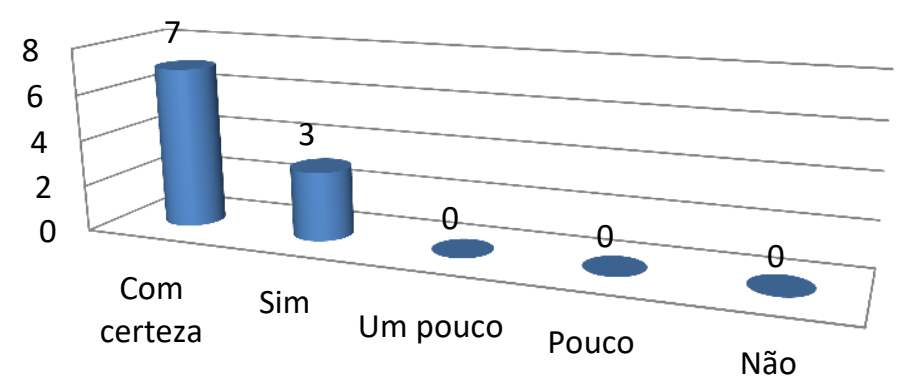

Fonte: Dados da pesquisa (2017)

Resultados sugerem a influência da metodologia adotada pela administração militar, em Petrolina, no índice de desempenho de seus estudantes, convergindo para os achados dos estudos de Benevides e Soares (2015). 
“O bom desempenho é resultado da união de planejamento pedagógico, boa estrutura de apoio ao processo de ensino e aprendizagem, corpo docente capacitado e disciplina", acredita o coronel Mansur, diretor do Colégio Militar de Salvador.

São efeitos progressivos que apontam como tais fatores são primordiais para o bom funcionamento de uma instituição escolar, fomentando resultados satisfatórios. Cabe ressaltar que pesquisadores não se detiveram para avaliar, em estudos quantitativos, o porquê deste fenômeno. A literatura diretamente ligada ao assunto é basicamente internacional (Benevides e Soares, 2015) e por isso nossa análise permeia aspectos teóricos que envolvem diretamente a gestão escolar.

Uma influência militarmente educacional introduz na instituição fatores como disciplina, constante monitoramento, respeito à hierarquia, além de possuir uma rotina assemelhada a instituições como o Exército, proporcionando assim disciplina e responsabilidade comportamental. São fatores que norteiam e dão base aos dados coletados na pesquisa influenciando diretamente nas expectativas do corpo docente em relação aos discentes .

\section{Percepção de alunos sobre a prática pedagógica e administrativa do Colégio Militar de} Petrolina-PE.

A análise das questões apresentadas aos discentes do Colégio da Polícia Militar de Petrolina, neste estudo, descreve a percepção desses alunos sobre a satisfação com o ensino ofertado pela instituição, importância para o futuro, opção pela escola e imagem do Colégio da Polícia Militar, conforme resultados apresentados a seguir.

Em relação ao ensino, foi feita a seguinte pergunta: Em relação ao ensino, sua escola comparada com a de seus amigos é? 
Figura 5 - Escola Militar em relação a escolas não militares

Em relação ao ensino, sua escola comparada com as outras é? 15

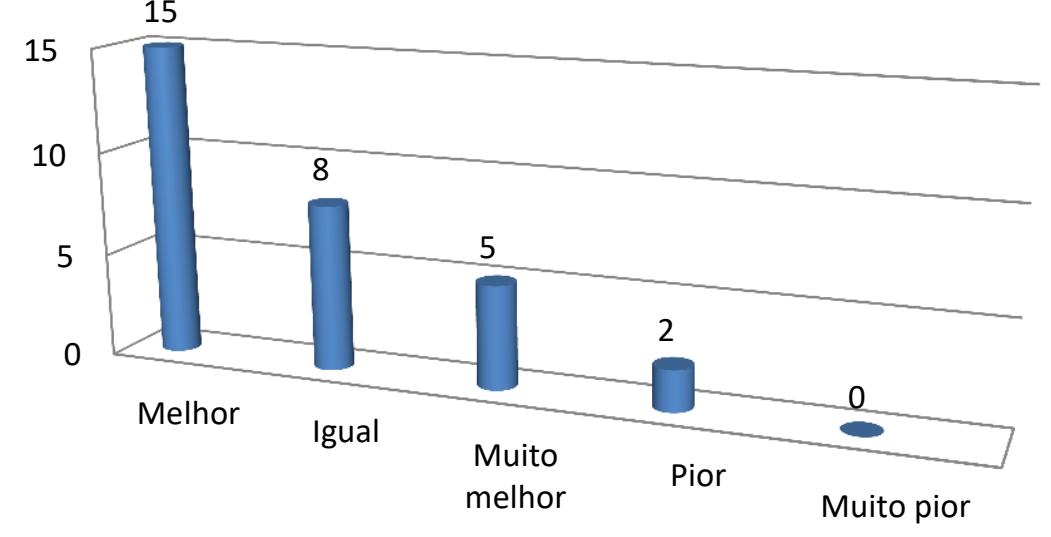

Fonte: dados da pesquisa (2017)

Resultados sugerem, a partir da percepção discente, que existe orgulho em pertencer à instituição. Essa sensação de pertencimento é apontada pela maioria (70\%) ao avaliarem a instituição entre "melhor" e "muito melhor" quando comparadas a outras instituições públicas de ensino. Questionados sobre a importância da escola para o futuro, metade dos respondentes avaliou como importante enquanto a outra parte afirmou ser decisiva para o futuro.

Quando perguntados sobre a decisão de estudar em Colégio Militar, nota-se a grande influência dos pais na decisão, conforme ilustrado na figura 6. 
Figura 6 - Percepção de discentes sobre a escolha pelo Colégio Militar

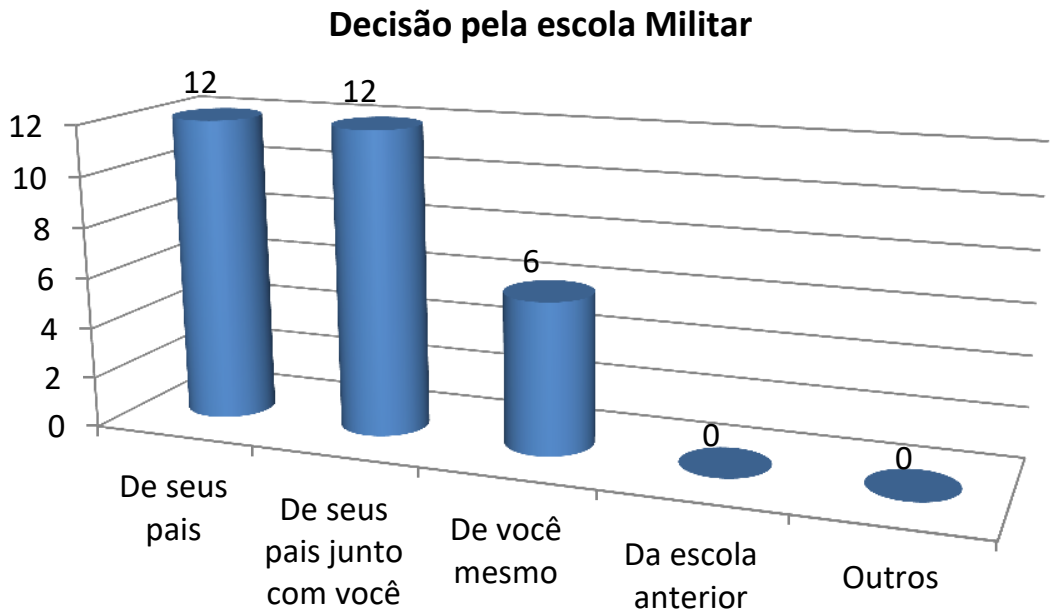

Fonte: dados da pesquisa (2017)

Esse resultado reflete a avaliação em relação à percepção discente sobre o diferencial do Colégio Militar, quando comparada a outras escolas públicas da mesma cidade, oportunidade em que a maioria das respostas remete às características da gestão militar, a exemplo de disciplina, professores capacitados e respeito às regras de convivência. Em que pese à opção por mais de uma resposta para o quesito, menos de um terço dos respondentes avalia que o diferencial tem relação com o interesse dos alunos, inferindo, nesse sentido, as contribuições da metodologia adotada pela gestão das escolas militares (BENEVIDES; SOARES, 2015). 
Figura 7 - Percepção discente sobre o diferencial da Escola Militar

Diferencial do Colégio da Polícia Militar em relação a outras escolas públicas de sua cidade

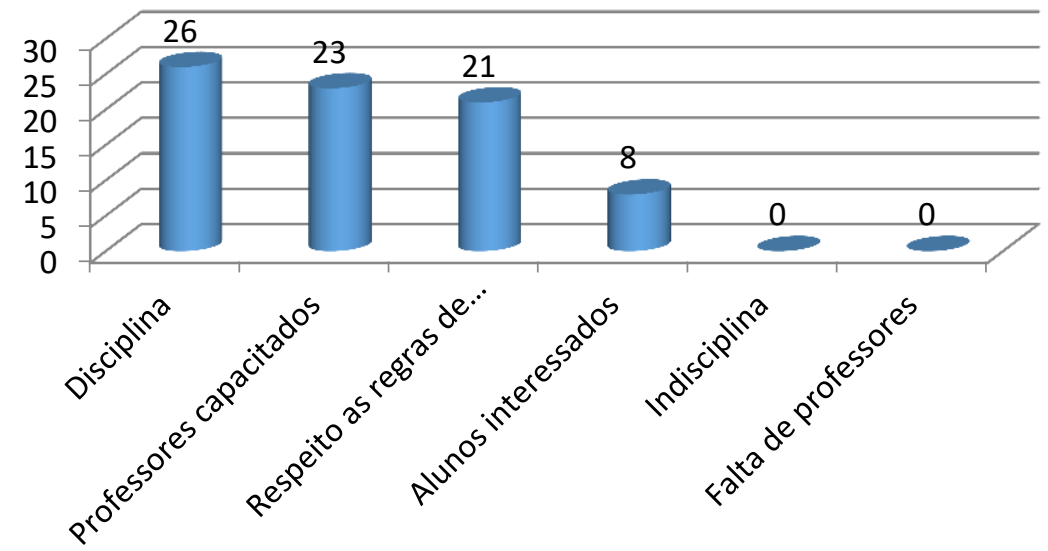

Fonte: dados da pesquisa (2017)

O que você acha que o Colégio da Polícia Militar tem de diferencial em relação às outras escolas públicas de sua cidade?

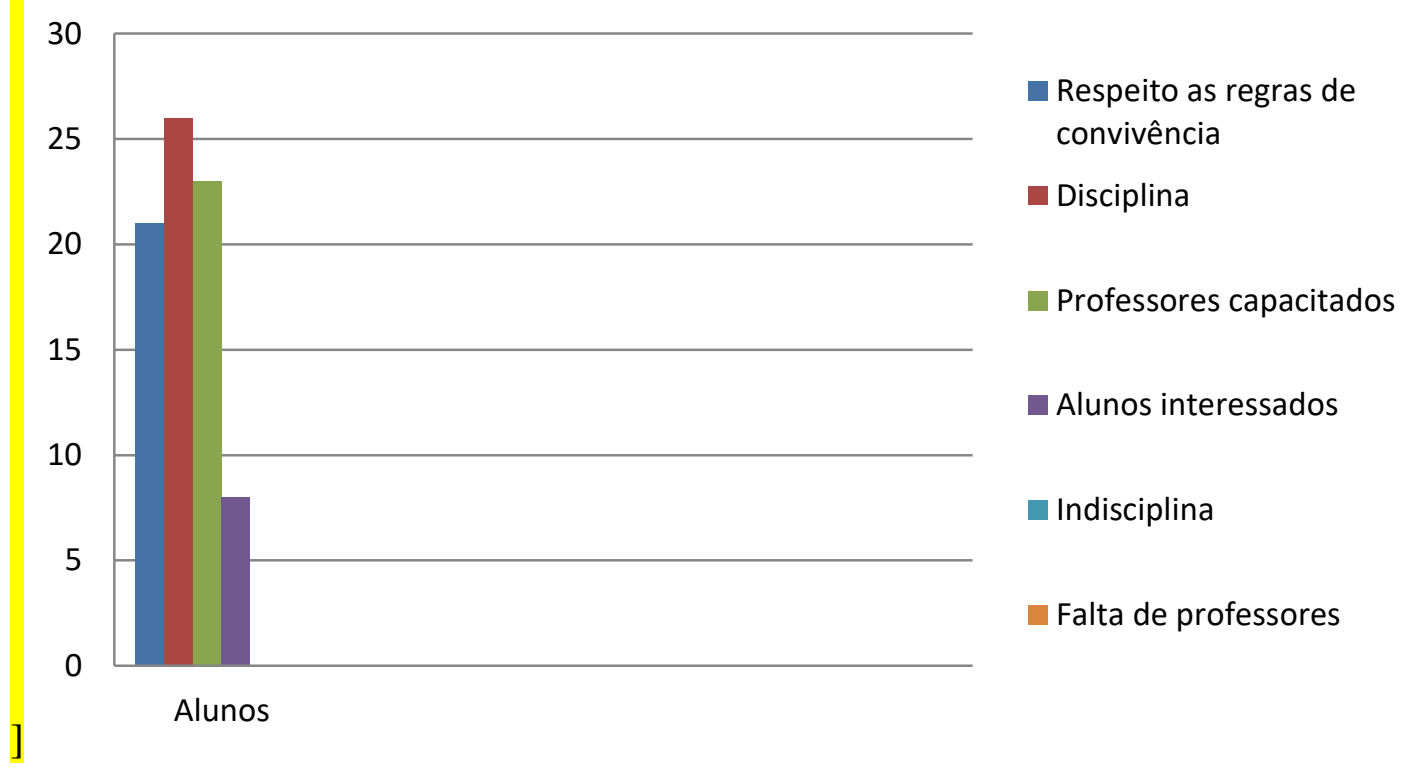


Aspectos como Disciplina, respeito às regras de convivência, capacitação de professores demonstrados na pesquisa acima corroboram para o referencial do Colégio Militar de Petrolina frente às escolas publicas da região.

Em uma pesquisa realizada pela revista ISTO É (2012) em diferentes escolas militares do Estado Brasileiro demonstrou que, do ponto de vista estrutural, essas instituições estão bem acima das escolas públicas. Além de possuírem um ambiente favorável a práticas esportivas com piscinas semiolímpicas, ginásios, quadra de tênis, o conhecimento prático através dos laboratórios de química, física, biologia e informática contribuem satisfatoriamente para o diferencial reconhecido pelos discentes. A capacitação dos docentes vem contribuir para o resultado da pesquisa. Esse corpo presente nas instituições militares é formado por doutores, mestres e especialistas que possuem regime de dedicação exclusiva.

O ponto de maior relevância apontado pelos discentes, gira em torno do fator disciplina. Como citado anteriormente, o modelo de regime militar adotado pelas escolas militares, além de influenciar na decisão dos pais na escolha pela gestão militar, é causa motivacional na decisão do corpo discente. A disciplina é rígida, influenciando na conduta ética e moral dos alunos.

\section{Considerações finais}

É evidente apontarmos que a Influência da Gestão Militar nas escolas públicas de ensino básico corroboram para a elevação do índice de desempenho dos estudantes. Diante desse aspecto, pontuamos o Colégio da Polícia Militar de Petrolina que apresenta resultados mais satisfatórios que as outras escolas públicas de ensino.

A relevância do Colégio da Polícia Militar de Petrolina apontada pelo INEP e o IDEB, situa a instituição como a primeira colocada no município de origem. Esses indicadores sugerem uma prática diferenciada que envolve, além de fatores pedagógicos, administrativos, éticos e morais, toda a gestão, corpo docente e discente da escola.

A colaboração desse estudo pode avaliar a satisfação dos professores em relação aos recursos disponíveis para o exercício de suas atividades. É relevante ressaltarmos que a gestão militar preocupa-se em proporcionar aos docentes e discentes equipamentos e espaços adequados e que somam no desempenho institucional. Esses aspectos contribuem para um 
feedback positivo dos docentes em relação aos gestores e demonstra como uma boa relação hierárquica favorece a execução dos objetivos internos.

Os efeitos progressivos da educação militar interferem positivamente na disciplina e responsabilidade do aluno. Esse impacto demonstra a preferência do discente pela instituição e de como sua visão de futuro constitui reflexo dos conceitos desse tipo de gestão.

Os resultados aqui encontrados certamente contribuirão para o desenvolvimento da gestão militar educacional.

\section{Referências}

BARDIN, L. Análise de Conteúdo. Lisboa: Edições 70, 2006.

BENEVIDES. Alesandra de Araújo; SOARES. Ricardo Brito. Diferencial de desempenho das escolas militares: bons alunos ou boa escola? 2015. Disponível em : <https://www.bnb.gov.br/documents/160445/960917/DIFERENCIAL DE DESEMPENHO DAS E SCOLAS MILITARES.pdf/7ae9ef81-9687-46cb-b501-766ccef1cba2>. Acesso em: 14 jun. 2017.

INEP. Disponível em: 〈http://portal.inep.gov.br/web/enem/enem-por-escola〉. Acesso em 26 de dezembro de 2016.

INEP. Censo Escolar 2013. Disponível em: 〈http://ideb.inep.gov.br/>. Acesso em 26 de dezembro de 2016.

SIQUEIRA, Cláudia Machado; GIANNETTI, Juliana Gurgel. Mau desempenho escolar: uma visão atual. Rev Assoc Med Bras, 2011, 57, p. 78-87. Disponível em:

<http://www.scielo.br/pdf/ramb/v57n1/v57n1a21.pdf $>$. Acesso em: 14 jun. 2017.

VERGARA, S. Constant. Projetos e Relatórios de Pesquisa em Administração. 7. ed. São Paulo, Atlas, 2006

VERGARA, S. Constant. Métodos de Pesquisa em Administração. 4. ed. São Paulo, Atlas, 2010.

Como citar este artigo (Formato ABNT):

BOMFIM, Andreia P.; DAMASCENO, Arielle B.; SOARES, Luciene S.dos S.; RODRIGUES, Luzia C.; FERNANDES, Sielton S. Influência da Administração Militar nas Escolas Públicas de Ensino Básico. Id on Line Revista Multidisciplinar e de Psicologia, 2017, vol.11, n.37, p. 484-499. ISSN: 1981-1179.

Recebido: 11.08.2017

Aceito: 05.09 .2017 